A LECTURE NOTE

\title{
AN INTRODUCTION TO GIS
}

\author{
Tara Prasad Avasthi \\ Department of Geography Education \\ star_avasthi@yahoo.com
}

\section{INTRODUCTION}

Geography is the science of place and space. Geographers ask where things are located on the surface of the earth, why they are located, how places differ from one another, and how people interact with the environment. Geographers also study the linkages between human activities and natural systems. Geographers were in fact among the first scientists to sound alarm that human induced change that environment were beginning to threaten the balance of life itself. They are active in the study of global warning, desertification, loss of biodiversity, climatic change, and ground water pollution, and flooding. There are two main branch of geography: human geography and physical geography. Human geography is concerned with the spatial aspect of human existence. How people and their activities are distributed in space, how they use and perceive space and how they create and sustain the places that make up the earth surface. Human geographers work in the fields of urban and regional planning, transportation, marketing real estate, tourism and international business. Physical geographers study patterns of climates landforms, vegetation, soils and water. They forecast the weather, manage land and water resources and analyze and plan for forests, rangelands and wetlands. Many human and physical geographers have skills in recent trends of geography as well as latest tool of planning and decision making like (GIS) Geographic Information System (http//www.esri.com, 2007).

There are very strong links between GIS and academic discipline of geography, which extend will beyond the commonality of titles. The academic discipline has been the home for much of the research, development and training for GIS practitioners and some see GIS as a major element in the discipline's 'survival package' for the foreseeable future in a period of consideration pressures on public sector funding for academic work (Gober et al. 1995).

\section{WHAT IS GIS ?}

The term GIS is fundamentally about the use of digital data to represent space and time. Specially, GIS means study and analysis of earth provides information with fact data from every corner of world then process the data and management scientifically and systematically. GIS is powerful set of tool for storing and retrieving at will, and transforming and displaying spatial data from the real world for a particular set of purpose. It's root is in geography and latest new branch of information technology. Furthermore, GIS is a computer based system that provides four sets of capabilities to handle geo reference data, data input, data management, data analysis and data output (Aronoff, 1989). Thus, GIS is a tool which enhance decision making and planning process. It led to numerous opportunities, those who have used GIS. It manage geographic data by computer based system. GIS is computer based system for mapping and analyzing things that exist and event that happen around us. Our everyday decisions are dependent on this type of analysis. With the rapid growth of GIS and related technologies, over the two last decades, GIS has became a vital element in maintaining and integrating geographic based information. In today's information society, GIS technology is moving into the mainstream of the information technology. Industry and virtually influencing the way we deal with many of problems, it helps us to solve problems such as locating a school, hospital or a faculty, solid west management, emergency vehicle routing, earth quake disaster mapping, natural hazard mapping, real state, business and many more (http:// www.icimod.org).

\section{WHY GIS ?}

GIS at least consists of database, map information and computer based link between them. GIS uses map computer based link between them. GIS uses map features to manage data and is flexible enough to carry out analysis modeling and even predictions. Almost all human activities and natural phenomena are spatially distributed, so all of them can be studied using GIS, in order to make vigorous decisions. One has to access various information of different sources of different dimensions presented in different maps should be combined, GIS is very efficient tool for such application, which has capability of integration of different spatial and statistical information into one system. Geography and geographic information describing it is part of 
our everyday world. Almost all decision is constrained influenced or detected by some facts of geography. This demands for geographic information parallels the need for GIS (http:// www.gw.geoplace.com).

\section{CONCEPT AND COMPONENTS OF GIS}

A geographic information system is a system for management, analysis, and display of geographical knowledge, which is represented using a series of information sets (Figure 1). The information sets include.

Maps and Globs: Interactive views of geographic data with which to answer questions, present results, and use as a dashboard for real work. Maps and globs provide the advanced GIS applications for interacting with geographic data.

Geographic Data Sets: File bases and databases of geographic information features, networks, topologies, terrains, surveys and attributes.

Processing and Work Flow Models: Collection of geoprocessing procedures for automating and repeating numerous tasks and for analysis.

Data Models: GIS data sets are more than database management system (DBMS) tables. They incorporate advanced behavior and integrity like other information systems. The schema, behavior and integrity rules of geographic data assets play a critical role in GIS.

Metadata: Documents describing the other elements. A document category enables users to organize, discover and gain access to shared geographic knowledge.

\section{QUESTIONS GIS CAN ANSWER}

What is at (Location): This question seeks to find what exists at a particular location. A location can be described in many ways using, for example, a place, home, or geographic reference such as longitude/latitude.

Where is it? (Condition): This question covers of the first and requires spatial data to answer, instead of identifying what exists at a given location. One may wish to find locations where certain conditions are satisfied.

What has changed since? (Trends): This question might involve both of the first two and seeks to find the differences within an area over time, e.g. changes in forest cover or the extent of urbanization over the last ten years.

What spatial pattern exists? (Patterns): This question is more sophisticated. It might be asked to determine whether landslide are occurring mostly near streams or to find out at which traffic points accidents are occurring most frequently.

What if? (Modeling): This question is posted to determine what happens if, for example, a rood is added to network or a toxic substance seeps into the local ground water supply (Geoinfosymstems.com/ welcome.htm).

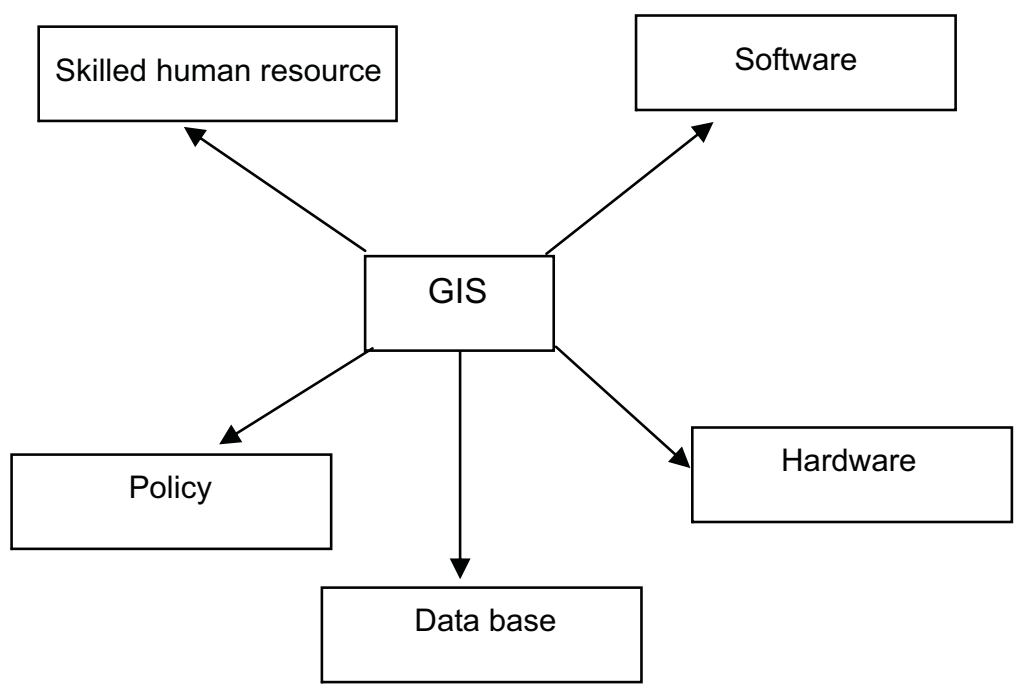

Figure 1: Components of GIS

\section{MAJOR FUNCTIONS OF GIS}

Data Capture: Data used in GIS often come from many different sources and are of many types and stored in different ways. A GIS provides tool and methods for the integration of different data into a format so that data can be compared and analyzed. Data sources are mainly manual digitization, scanning of aerial photographs, paper maps and existing digital data. Remote sensing, satellite imagery and GPS are also input sources of GIS data.

Database management: After data are collected and integrated a GIS provides facilities that can contain 
and maintain data. Effective data management includes the following aspects: Data security, data integrity, data storage and data retrieval and data maintenance.

Spatial Analysis: In addition to-providing a graphic query tool to access database records, GIS provides spatial analysis tools. Spatial analysis involves comparing the location of any two features and determining if the two features touch, are near each other, share a common side (adjacent), sit directly on top of each other (coincident), are inside the same area or region, etc. This capability sets GIS apart from any CAD package, automated mapping or database system. This distinguishing characteristic allows the GIS to perform network tracing, distance searches, compute intersections between map layers, and combine data layers together to form new information. It is the most important function of a GIS that makes it distinct from other system such as Computer-Aided Design and Drafting (CADD). Spatial analysis provides functions such as spatial interpolation, buffering and overlay operations

Presenting Results: One of the most exciting parts of GIS are the variety of ways in which the information can be presented once it has been processed. Maps and threedimensional images can supplement traditional methods of tabulating and graphing data. These capabilities have given rise to new fields such as exploratory cartography and scientific visualization. Visual presentation is one on the most remarkable capabilities of GIS that allows for effective communication of results (http/ www.esri.com)

\section{APPLICATION OF GIS}

Application is general terms covering all things that "go

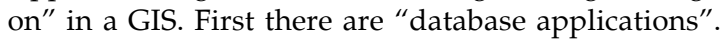
There are all the functions needed to create, edit, build and maintain the database and are usually carried out by the GIS system staff. But GIS provides many simple applications or part of the initial software package, for example, map display query etc. Most GIS have a macro programming language for this purpose i.e. Arc Macro Language (AMI) in ArcInfo, avenue in ArcView and user interface macro and VBA in ArcGIS.

The GIS technology is rapidly becoming a standard tool for management of natural resources. It is used to assist decision makers by indicating various alternatives in development and conservation planning and by modeling the potential outcomes of series of scenarios. It should be noted that any task begins and ends with the real world, data are collected about the real world. After the data are analyzed, information is compiled for decision makers. Based on this information, actions are taken and plans are implemented in the real world. Some typical examples of GIS application within natural planning are
- Land use planning and management

- Mineral exploration

- Environmental impact studies

- Management of natural resources

- Natural hazard mapping

- $\quad$ Forestry and Wildlife management

- Soil degradation studies

- Monitoring desertification

- Agricultural development

- Location Planning

- urban Rural Planning

- Natural Resource Management

- Water Resource Management

- Hazard Management

- Lands use mapping

- Topographic mapping

- $\quad$ GPS, RS mapping

\section{IMPORTANCE OF GIS}

GIS is a tool to enhance the student's understanding of social and natural phenomena on a local and global scale in a way most learners are comfortable with due to their everyday use of computers for applications like gaming and communication (Donert K., 2005).

Learners are able to allocate, interpret, arrange data, develop maps, work with a web-GIS, simulation and demonstration, and work on a united board. It is necessary in any kinds of spatial geography and scientific questions as well as in education because it is a tool to analysis, visualizes restructure etc (http:// www.niace.org.uk)

It allows students to broaden their awareness of big issues like global economy and globalization process enables global access to data and collaboration with others. This also allows the possibility of e-learning, finding information on the web, collecting and evidence of learners work, communicating with planners, potentiality for contact across national boundaries could be developed more (http:/ /ww.jisc.ac.uk.)

\section{REFERENCES}

Aronoff, S. 1989. Geographic Information System: A Management Perspective. Ottawa: WDL Publishers

Donert K. 2005. The Use of ICT in Geography, Department in European Education HERODOT Network.

Gober, P.A. Glasmeier A.K., Goodman J.M. Plane D.A., Wood J.S. 1995, Employment Trends in Geography. The Professional Geographers. Vol...

http/www.geoinfosystems.com/welcomehtml.

http://gis.about.com/science/gis

http://ww.niace.org.uk/information/brifing sheets / 41Europe.pdf.

http://www.esri.com

http://www.gw.geoplace.com

http://www.icimod.org.

http://www.jisc.ok.uk. 